\title{
Prof. Dr. Roberto Caldeyro-Barcia
}

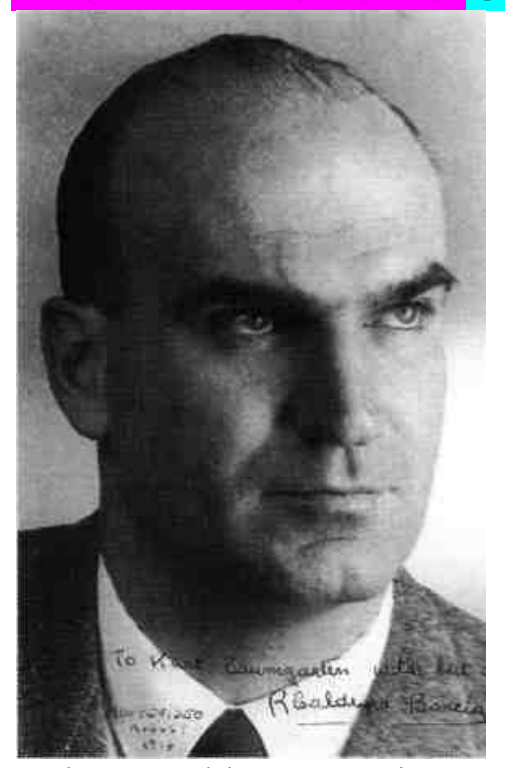

Roberto Caldeyro-Barcia wurde am 26.9.1921 in Montevideo, Uruguay, geboren. 1939 begann er sein Medizinstudium und fiel sehr bald seinen Lehrern als an physiologischen Problemen interessiert auf. Seine rege Mitarbeit am physiologischen Institut brachte ihm sehr bald mehrmonatige Studienaufenthalte in Europa und Amerika, u.a. auch bei zwei Nobelpreisträgern, den Professoren Heymans in Belgien und Houssay in Amerika. Es wundert daher nicht, dass er schon ein Jahr nach seiner Promotion Assistentprofessor und drei Jahre später (1950) Associate Professor am physiologischen Institut seiner Heimatuniversität wurde.

Seine Freundschaft mit dem Vorstand der Universitätsfrauenkli-nik in Montevideo ermöglichte ihm schon früh uterusphysiologische Studien in diesem Kreissaale anzustellen.

1959 wurde er auf Grund seiner aufsehenerregenden Ergebnisse, die er mit seinem väterlichen Freund und Mentor, Prof. Hermogenes Alvarez, erarbeitet hatte, Ordinarius für Physiopathologie im neu für ihn errichteten Department für Physiopathologie am damals mo-dernsten Universitätskrankenhaus Südamerikas in Montevideo. Der 'Piso 16' dieses Hauses wurde innerhalb weniger Jahre zum Mekka

aller perinatologisch Interessierten der ganzen Welt. Mit Unterstüt-zung der WHO, genauer der panamerikanischen Gesundheitsorgani-sation, entstand daraus das CLAP, das lateinamerikanische Zentrum für Perinatologie, welches er bis 1986 leitete. 1981 erhielt er den ersten Lehrstuhl für Perinatalmedizin der Welt.

Seine wissenschaftlichen Leistungen sind Allgemeingut der Perinatalmedizin geworden. Schon 1947, eben promoviert, gelang ihm mit Alvarez die erste intrauterine Amniondruckmessung. Auf Grund dieser Untersuchungsergebnisse konnte er eine ganze Reihe bisher gültiger Theorien über die Uterusmotilität widerlegen. 
1950 berichtete er über die Resultate der von ihm angegebenen simultanen intramyometralen Druckmessung, die Aufschluss über den Erregungsablauf der Kontraktionswellen am Uterus gab (Triple descending gradient).

1958 berichtete er erstmals am FIGO Weltkongress für Gynäko-logie über eine kontinuierliche Registrierung der mütterlichen We-hentätigkeit und der von dieser beeinflussten fetalen Herzfrequenz. Dies was die Geburtsstunde der Kardiotokometrie, ohne welche eine moderne Geburtsüberwachung nicht mehr denkbar ist.

Er hielt unzählige Vorträge in der ganzen Welt, sein Institut bilde-te über 300 von ihm selbst ausgesuchte Perinatologen a,. " die seine Lehre auf dem ganzen Globus verbreiteten. Der schon in ju $\mathrm{u}^{1 / 8 \mathrm{en}}$ Jah-ren Vielgeehrte wurde dreifacher Ehrendoktor und siebenfacher Eh-renprofessor an amerikanischen und europäischen Universitäten. Sieben wissenschaftliche Akademien ernannten ihn zum Ehrenmit-glied. Zudem gibt es praktisch keine nennenswerte Gynäkologenge-sellschaft der Welt, deren Ehrenmitglied er nicht ware. Das gleiche gilt für die Gesellschaften für Perinatologie.

Trotz seines frühen Ruhmes is Caldeyro bis zuletzt immer ein bescheidener, von alien geliebter und bewunderter Mensch und Leh-rer geblieben.

Zum Beweise hiefür sei daran erinnert, dass keine seiner mit seinen Mitarbeitern publizierten Entdeckungen, bzw. Erkenntnisse seinen Namen tragen (Alvarez Wellen, Oxytocinbelastungstest nach Pose, Poseiroeffekt und nicht zuletzt die Grössendefmition für die Uterusaktivität, die Montevideoeinheiten).

In den letzten Jahren seines stets aktiven Lebens widmete er sich - wohl auch aus Dankbarkeit für die vielen Gebärenden, an denen er seine Studien durchführen durfte - der Humanisierung der Geburts-hilfe. Zu diesem Zwecke gründete er 1982 das Maternal Child Health Programm, dessen wissenschaftlicher Direktor er bis zu seinem Lebensende blieb. Am 2. November 1996, nur wenige Wochen nach seinem 75. Geburtstage, verstarb Roberto Caldeyro-Barcia in seinem Hause an der Bucht von Montevideo.

Die Geburtshilfe verliert mit ihm einen ihrer Grössten. Über 300 seiner engsten Schüler verlieren einen greisen, bewunderten Lehrer, Förderer und Freund. Die Zahl der Kinder, welchen durch dir Befol-gung seiner Lehren ein optimaler Start ins Leben ermöglicht wurde, ist Legion. Dadurch hat er sich ein bleibendes Denkmal gesetzt!

K. Baumgarten

KARGER C1996S. KargerAG, Basel

E-Mail karger@karger.ch Fax+4161306 1234 http://www. karger. ch 